\title{
Dynamics of Leadership Styles And the Management of Small Businesses in Nigeria
}

\author{
Zirra, Clifford Tizhe Oaya (Fcpa,Mba) ${ }^{1}$, Ezie, Obumneke ${ }^{2}$ \\ ${ }^{I}$ Department Of Business Administration Faculty Of Administration Nasarawa State University, Keffi, Nigeria \\ ${ }^{2}$ Department Of Economics, Bingham University, Karu, Nasarawa State, Nigeria
}

\begin{abstract}
Overtime, it has been identified that the major problem facing many businesses and other institutions are poor attitude to work among the workforce, inefficiency and ineffectiveness of leaders in most places. The study thus examined the dynamics of leadership style towards the management of small business in Nasarawa state. A causal comparative research design based on the performance of SMEs business owners was used; while the t-test of the ordinary least square (OLS) regression method of analysis was employed for data estimation and test of hypothesis. Findings from the study revealed that Transactional leaders' behaviours have been influential towards business expansion and made them more aware of the task outcomes. The SMEs employees were discovered to be very much fulfilled when their manager delegated almost all authority and control to them; while Transformational leadership was discovered to have a significant impact on innovative procedures. The study thus recommends that SMEs managers should ensure greater acquisition of market share that enhances business expansions; Guide to be rewarded for their work; be satisfied when others meet agreedupon standards; provide recognition or rewards to motivate their employees. More so, managerial policies which call for greater involvement should be sustained in guiding subordinates to achieve organizational goals.
\end{abstract}

\section{Introduction}

Leadership has been a topic of interest, speculation and debate. Since the time of Plato, studies on leadership have examined leaders focusing on what leaders do in the physical world of human beings. One principal factor which makes organisations to survive, grow and adapt to environmental challenges is leadership (Rossouw and Vuuren, 2013). The distinction between successful and unsuccessful organisations can be attributed to differences in the levels of intellectual development and effectiveness of leadership in each group (Goleman, 2000).

Kim (2004) is of the view that the kind of leadership style exhibited by managers to a large extent influences organizational valued outcomes such as low employee turnover, reduced absenteeism, customer satisfaction, and organizational effectiveness. Similarly, leadership style controls interpersonal, reward and punishment that shapes employee behaviour, motivation and attitude which impacts on organizational performance (Warrick, 1981). It can either lead to inspiration or disenchantment among employees resulting in increase or decrease productivity (Sander, 2007). Furthermore leadership style at the workplace can affect employee's self-image either positively or negatively particularly an employee's health and energy level by creating a stimulating work climate or one filled with tension or fear (Warrick, 1981).

The debate over whether leadership style can lead to firm performance has largely been contested. Those who support the veracity and efficacy of leadership style and firm performance believe that the disposition of leaders, their roles and responsibilities in decision-making assist organizations to find solution to challenges and adapt

to the complex competitive environment which impact on profitability (Bass, 1991; Waldman \&Yammarino, 1999). The literature revealed that without good decisions organizations would lack competitive advantage. In contrast, other theorists believe that organizations which are less endowed resourcefully are so disadvantaged that on its own leadership is too weak to influence performance except through the combination of several factors (Hanna \& Freeman, 1989; Meindl, 1990). Though the view seems reasonable, empirically, evidence suggested that leadership plays limited distinguishing role in influencing organizational members towards firm performance are scanty

\subsection{Statement of the problem}

Although, there has been increase in literatures on leadership and organisational performance in small and medium enterprises (SMEs) most of them are either foreign based or lack empirical data to justify the essence of leadership in SMEs within the Nigerian context. In fact, majority of empirically based literature focus on leadership in large organisations on the premise that the findings could be generalised to other categories of business organisations.Given the significant role of SMEs in the Nigerian economic development, the need for this sub-sector to catch up with their counterparts in the globalised world cannot be overemphasized. 
More so, the fact that leadership is always identified as the missing link (Amanda and Hodgkinson, 2006) cannot be underestimated.

The study provided answers to the following questions:

i. What relationship exists between Transactional leadership and SMEs business expansion?

ii. To what extent has Laissez-faire Leadership significantly influenced the employee job satisfaction?

iii. What impact does Transformational leadership has on SMEs Innovation?

A hypothesis is the tentative statement of the relationship between two or more variables .It is a statement of assumption, written down by researcher in order to assist him or her. It could be either wrong or right. It is the desire or intension of this research work to find out the impact of effective leadership and organizational development and then make necessary recommendation based on the findings.

$\mathbf{H}_{01}$ : There is no significant relationship between Transactional leadership and SMEs business expansion

$\mathbf{H}_{\mathbf{0 2}}$ :Laissez-faire Leadership has not significantly influenced the employee job satisfaction

$\mathbf{H}_{\mathbf{0} 3}$ :Transformational leadership has no significant impact on SMEs Innovation.

\section{Literature Review: Conceptual, Empirical and Theoretical Discourse 2.1The Concept of Small and Medium Scale Enterprises (SMEs)}

For decades, the Small and Medium business have been found to constitute the very foundation upon which the large businesses were built. However, small and medium have been identified differently by various individuals and organization such that an enterprise that is considered small and medium in one place is seen differently in another. Even within a country, the definition changes over time. Some common indicators employed in the various definitions include total assets, size of labour employed, values of annual turnover and capital investment (Baenol, 1994).

The small scale industries of Federal Ministry of Industries defined small scale as " enterprises having capital (investment in land, building, machinery and equipment and working capital) up to N60,000.00 and employing not more than 50 person" as far back as 1979. The Central Bank's monetary and credit guidelines, small-scale industries were regarded as establishment whose annual turnover is less than N6million and capital not exceeding N10million. According to Brwon, Medott and Hamitton (1990), Many Small firms are created as a last resort rather than as first choice and have therefore invited growth potential.

Ayaggari (2003) and Beckley (1988) contends that the "definition of small and medium scale enterprises varies according to context, author and countries". In country such as USA, Britain and Canada small scale business is defined in terms of annual turnover and the number of paid employees. (Ekpeyong and Nyang, 1992) In Britain for example small scale business is conceived as that industry with annual turnover of 2 million pounds or less with fewer than 200 paid employees.(Ibid; 4) In the case of Japan it is conceptualized as type of industry, paid up capital and number of employee. Consequently small and medium scale enterprises are defined as those manufacturing with 100million yen paid up capital and 300 employees. Those in wholesale trade with 300million paid up capital with 100 employees while those in retail trade with 100million paid up capital with 50 employees (Fatai, 2012)

In the case of Nigeria hardly do you see a clear-cut definition that distinguishes between small and medium scale enterprises. However, the Central Bank of Nigeria in its monetary policies circular No. 22 of 1988 viewed small scale industry as those enterprises which have annual turnover not exceeding 500,000 naira.(CBN, 2011) Similarly in 1990 the Federal Government of Nigeria defined small scale enterprises for the purpose of commercial bank loans as those enterprises whose annual turnover do not exceed 500,000 thousand naira and for merchant bank loan those enterprises with capital investment not exceeding 2 million naira (excluding the cost of land) or a minimum of 5 million naira.

In a more general and comprehensive term Ogechukwu (2006) chronicled a general criteria for defining small and medium scale enterprises in different countries. These includes number of employees, annual turnover, local operations, sales volumes, financial strength, managers and owners autonomy, relatively small markets compared to their industries and capital usually supplied by individual or shareholders etc. As a result of this definitional differences and lack of universal definition, the European Union in 2003 adopted a universally accepted definition of small and medium scale enterprises and micro business as companies with less than 250 employees, with respect to financial criteria, revenues must not exceed 50 million Euro(measure as turn over) or 43million euro(measure as balance sheet) In addition, the European Commission specifies term of ownership stating SMEs must be independent with less than $25 \%$ being owned by outside interest.(European Commission; 2007). In a report of enterprises association, Macqueen (2004) conceive of SMEs as enterprises employing 10-99 full time employees or with a fixed capital investment of US\$1000-500,000.

Small and medium scale enterprises are certainly not transnational company, multinational cooperation, publicly owned enterprises or large facility of any kind. However they can depend on business and ownership structure to become a large business unit (Macqueen 2006) while it can be argued that $80 \%$ of the financing of 
SMEs come from owners, friends and families, business form can take different form including private ownership, limited partnership, contract and sub-contracts, cooperatives or associations (Kozak, 2007). Small and medium scale enterprises have a narrow context within which its operation is carried out. However, where it is effectively operated it has capacity to sprout the economic growth and development.

\subsection{Empirical Review}

Literature review shows that knowledge about leadership and its impact on SMEs performance is still lacking especially leadership behaviours of leaders within Nigerian businesses. Entrepreneurs are needed to develop solid leadership behaviours in order to take their firms into good and bad times. Appropriate leadership behaviour within the enterprise will keep employees to stay focused and be motivated especially at times of crisis. Abdul Razak (2010) suggested that a development of good leadership is one of the driving forces for the success of SMEs in the future, and evidences suggest that inadequate leadership and management skills as primary factors contributing towards the failure of SMEs (Davies 2002). Therefore, it is acknowledged that an enterprise requires entrepreneurship, but what is needed to maintain the operation and guide an enterprise to success is the leadership that exists within the organization (Arham 2011).

Valdiserri and Wilson (2010) postulated that leadership style is critical to the success of a small business and Hernez-broome and Hughes (2004) suggested that leaders of small businesses need to develop a better understanding of leadership behaviour in order to achieve their organisational goals and objectives. For example, Valdiserri and Wilson (2010) studied 48 small businesses in West Virginia and Pennsylvania and suggested that transformational and transactional leadership behaviours contributing to the profitability and success of small businesses.

At the same time, some researchers contend that failures of small businesses are associated with poor leadership (Ihua, 2009; Beaver, 2003). Beaver (2003) in his observation of subjective and empirical research on the success and failures of small business concluded that, a large proportion of the causes of small business failures are attributed to internal factors of the firm, such as poor leadership and lack of management abilities among the key players in the firms. Recent empirical findings by Ihua (2009) which compared the key failure factors of SMEs in the UK and Nigeria revealed that poor management and lack of leadership was found to be the most crucial factor influencing SMEs failures in the UK while poor economic conditions and infrastructural inadequacy were found to be the most crucial factors in Nigeria. He concluded that this internal factor needs to be given more attention by the policy makers in the UK in order to improve the success of entrepreneurial firms.

McGrath and MacMillan (2000) are of the view that there is a significant relationship between leadership styles adopted by managers and performance of the organizations. Effective leadership style is seen as a potent source of management development and sustained competitive advantage, leadership style helps organization to achieve their current objectives more efficiently by linking job performance to valued rewards and by ensuring that employees have the resources needed to get the job done. Sun (2002) compared leadership style with the leadership performance in schools and enterprises, and found that leadership style had a significantly positive correlation with the organizational performance in both schools and enterprises.

Fu-Jin et al. (2010) opine that when executives use their leadership style to demonstrate concern, care and respect for employees, it would increase interest of employees in their work and enable them to put up better performance, thereby affecting their job satisfaction positively. Understanding the effects of leadership on performance is also important because leadership is viewed by some researchers as one of the key driving forces for improving a firm's performance. Effective leadership is seen as a potent source of management development and sustained competitive advantage for organizational performance improvement (Avolio, 1999; Rowe, 2001)

\subsection{Theoretical Framework: Leadership Theories}

Organizations have been with humanity more than two centuries but despite the perceived influence of leadership on organizational performance, empirical research into leadership only commenced in the 1900s. Since the generation of interest in the concept, the body of knowledge has been growing fast with some over 350 definitions on the subject matter (Hamidifar, 2009). To offer a comprehensive definition which encapsulates all leadership attributes would be very difficult (Bass, 1985), but the basic tenets of leadership are about influencing relationships among leaders and followers which generates effective behavior toward reaching defined organizational goals and objectives. Yukl (1994) pointed out that leadership is a process of having remarkable influence on the subordinate in which he or she is motivated to achieve a specified target and beyond, the group maintain cooperation and achieve stated objectives. Fry (2003) is also of the view that leadership is a strategic process of offering inspiration to enhance the employee's potential for growth and development by the leader. Northouse (2004) asserts that leadership is where any individual influences a group of people to achieve common goals. The contribution by these researchers to the concept of leadership points to the fact that leadership is a positive but persuasive (influential) action which generates inspiration among followers and directs effort towards accomplishing specified individual, team, and organizational objectives. 
Leadership is indispensable; it is needed in business, political, educational, and social organizations for the attainment of goals .

\subsubsection{Laissez Faire Leadership Style}

The main emphasis of this leadership style is neither on performance nor people. The philosophical assumption is that naturally human beings are unpredictable and uncontrollable and trying to understand people is a waste of time and energy. On this hypothesis, the leader tries to maintain a low profile, respects all constituencies within the organization, tries not to create waves of disturbance, and relies on the few available loyalists to get the job done.

Laissez-faire leader lives and work with whatever structure put in place without any suggestions or criticisms.Goals and objectives are established only when necessary and required. The leader is not control-frisk and abdicates controlling to employees. He or she shuns decision-making as much as possible and would like to avoid communication but communicates only when needed. Thus, the business of employee development is not a concern to the laissez faire leader who believes that employees can take care of themselves.

\subsubsection{Autocratic Leadership Style}

Autocratic Leadership Style (ALS) places more emphasis on performance and low emphasis on people. The focus of power is with the leader and all interactions within the group move towards the leader (Mullins, 1999).The leader unilaterally exercises all decision-making authority by determining policies, procedures for achieving goals, work task, relationships, control of reward, and punishment (Mullins, 1999).

The basic assumption underlying autocratic leadership style is based on the premise that, people are naturally lazy, irresponsible, and untrustworthy and leaving the functions of planning, organizing, and controlling to subordinate would yield fruitless results and so such functions should be accomplished by the leader without the involvement of people. McGregor (1960) described the autocratic leader as the Theory X manager with the same set of theoretical assumptions as Taylor's scientific management and Schein's (1988) rational-economic model.

Further, Likert's (1961) four management systems, characterized autocratic leadership style system as an exploitative-authoritative system where power and direction come from the top downwards, where threats and punishments are employed, and where communication is poor and team-work is non-existent (Cole, 2004). Tannenbaum and Schmidt (1957) described an autocratic leadership style on a continuum and opined that autocratic leaders make decisions and announce them, without inviting suggestions from subordinates.

Warrick (1981) concurs that autocratic leader relies heavily on authority, control, power, manipulation and hard work to get the job done. In the autocratic leadership system, formal centralized structures, procedures, processes and mechanism are clearly defined and are enforced to ensure that subordinates do their jobs efficiently within the rules. Punishments are often applied when mistakes are made and sanctions are in the form of withholding attention or good assignment or making people feel guilty. Motivation under this leadership style is by the means of economic incentives which are extrinsic in nature and based on performance. Development within an autocratic system comes from hard work and rarely does delegation of authority practiced.

Most theorists have identified autocratic leaders with authoritarian leaders simply because research has proven that there is a strong positive correlation between autocratic leadership style and authoritarianism (Bass, 1990; Choi, 2007; White \& Lippitt, 1960). Authoritarian leaders depend on their power as weapon for coercion.

Although Autocratic Leadership style is characterized with high productivity it often results in counter resistance of opposition which restricts output. The increase in productivity happens when the leader is present and the leadership style improves worker performance in relatively simple tasks (Gustainis, 2004).Warrick (1981) opined that ALS breeds hostile attitude, conflicts, distorts and guards communication, high turnover, absenteeism, low productivity, and affects work quality. The style also breeds yes-men who lack creativity and innovation and all they know is the adherence to rules, procedure, red-tape, and status seeking symbols and often afraid of taking responsibility because by doing so they risk committing punishable mistakes that would lead to demotion.

\subsubsection{Democratic Leadership Style}

Mullins (1999) is of the view that democratic leadership style focuses more on people and there is greater interaction within the group. The leadership functions are shared with members of the group and the leader is more of part of the team (Mullins, 1999). Similarly, Luthar (1996) and Wilson et al. (1994) concurred that the principles of democratic leadership is friendliness, helpfulness, and the encouragement of participation. In the same vein, McGregor (1960) described this leadership style as benevolent, participative, and believing in people. He equated democratic leader to the Theory Y manager which is associated with increased follower productivity, satisfaction, involvement, and commitment (Hackman, Johnson, \& Choi, 2007). 
The philosophical assumption underlying democratic leadership style is that naturally all people are trustworthy, self-motivated, like responsibility and challenging work and so encourages organizational conditions to foster teamwork, high performance and satisfaction (Warrick, 1981). The emphasis of this leadership style is on performance and people.

Based on the theoretical explanation of democratic leadership style, the researchers found that planning within a democratic leadership system is accomplished with heavy employee involvement with objectives that are transparently and clearly established with its accompanying performance targets. Decision-making in a democratic system is decentralized and flexible with clearly defined responsibilities and an open participative work environment. Punishments as a form of reprimand are the last option and high performance is recognized and rewarded. Conflicts are openly confronted by addressing the causative factors and not personalities.

Democratic leadership style results in high employee productivity, satisfaction, cooperation, and commitment. It reduces the need for controls and formal rules and procedures which result in low employee absenteeism and turnover. The leadership style develops competent and committed employees who are willing to give their best, think for themselves, communicate openly, and seek responsibility (Bass, 1990). With all the positive attributes associated with democratic leadership style, decision-making becomes over-stretched since opinions and lengthy debates play a key part in the process (Denhardt \& Denhardt, 2003).

\section{III.Research Methodology}

The research design adopted for this paper is the causal comparative research design. This is a kind of research in which the researcher cannot manipulate the data that is being used. Kerlinger (1973) describes it as a design used when the researcher intends to determine cause-effect relationship between the dependent and independent variables with a view to establishing a causal link between them.

The population of the study covered SMEs operators in Nasarawa state, Nigeria. This research utilized the content analysis technique which is a research method for making replicable and valid inferences from data, to operationalize the effective leadership variables. The study made use of primary sources of data in eliciting the required information needed for this research.The $\operatorname{Smith}(1984)$ formula was used in the determination of the sample size for the study.

The sample was based on the formula:

$n=\frac{N}{3+N(e)^{2}}$

Where;

$\mathrm{n}=$ sample size;

$\mathrm{N}=$ population size;

$\mathrm{e}=$ Level of precision required;

$3=$ constant

In determining the sample size, the following variables were used:

Confidence interval $=95 \%$

$\mathrm{e}=$ Margin of error $=0.05$

Substituting into the formula,

Sample size for the number of SMEs to be used:

$n=\frac{N}{3+N(e)^{2}}$

Table 1: Selected SMEs in Nasarawa State, Nigeria

\begin{tabular}{|l|l|c|}
\hline \multicolumn{1}{|c|}{ S/N } & \multicolumn{1}{|c|}{ Regions of Operations } & Population \\
\hline 1 & Lafia Region & 462 \\
\hline 2 & Keffi Region & 228 \\
\hline 3 & Akwanga Location & 145 \\
\hline & \multicolumn{1}{|c|}{ Total } & $\mathbf{8 3 5}$ \\
\hline
\end{tabular}

Source: Field Survey 
$n=\frac{N}{3+N(e)^{2}}$

Where,

$\mathrm{n}=$ sample size;

$\mathrm{N}=$ population size;

$\mathrm{e}=$ Level of precision required;

$3=$ constant

In determining the sample size, the following variables were used:

Confidence interval $=95 \%$

$\mathrm{e}=$ Margin of error $=0.05$

Substituting into the formula,

$n=\frac{N}{3+N e^{2}}$

$n=\frac{835}{3+835(0.05)^{2}}$

$n=\frac{835}{3+835(0.0025)}$

$n=\frac{835}{3+2.0875}$

$n=\frac{835}{5.0875}$

$n=164$

Table 2: Selected SMEs in Nasarawa State, Nigeria

\begin{tabular}{|l|l|c|c|}
\hline \multicolumn{1}{|c|}{ S/N } & \multicolumn{1}{c|}{ Regions of Operations } & Population of SMEs & Sampled Per SMEs \\
\hline & & & $\frac{164 * 462}{835}=90$ \\
1 & Lafia Region & 462 & $\frac{164 * 228}{835}=44$ \\
\hline 2 & Keffi Region & 228 & $\frac{164 * 145}{835}=30$ \\
\hline 3 & & & $\mathbf{1 6 4}$ \\
\hline Total & & 145 & \\
\hline
\end{tabular}

Source: Field Survey, 2017

was the instrument used in data collection and distribution; and the respondents were required to read each question carefully and indicated their agreement or disagreement with the statements using a 5 - point likert scale. Response for the statements was therefore keyed using a Likert type scale ranging from: $5=$ strongly agree $4=$ agree $3=$ undecided $2=$ disagree $1=$ strongly disagree.

\section{for Data Analysis and Model Specifications}

Quantitative analysis was used for the purpose of this study. This is because quantitative analysis results provide support for anticipated directions of the association between independent and dependent variables, therefore the study used regression analysis (OLS) to address the three hypotheses of this study since the study addressed relationship between the various variables. This was achieved by the use of E-view 7.0 The major statistical analysis that was used in this study was the ordinary least square (OLS) regression analysis- the simple regression analysis. This analysis was used in order to find the linear relationship between the independent variables.

The model specifications here are formulated to tests the three hypotheses and they are as follows:

$$
\begin{aligned}
& B E=\beta_{0}+\beta_{3} \text { TRSL }+\mu_{t}-----------1 \\
& E S=\beta_{0}+\beta_{2} L F L+\mu_{t}---------2
\end{aligned}
$$


$I N V=\beta_{0}+\beta_{1} T R F L+\mu_{t}----------3$

Where;

$\begin{array}{lll}\text { LFL } & = & \text { Laissez-faire leadership } \\ \mathrm{BE} & = & \text { Business expansion } \\ \mathrm{ES} & = & \text { Employee satisfaction } \\ \mathrm{INV} & = & \text { Innovation } \\ \text { TRSL } & = & \text { Transactional leadership } \\ \mathrm{TRFL} & = & \text { Transformational leadership }\end{array}$

Vi. Results And Discussion

The results obtained under this section were generated using OLS regression analysis. The three hypotheses formulated in the study were tested using student t-statistics. The level of significance for the study is 5\%, for a two tailed test. The decision rule is that we shall accept the null hypothesis if the critical t-value $( \pm 1.96)$ is greater than the calculated value, otherwise reject the null hypothesis. That is, using the student $t$-test ( $t$-statistic), we say that a variable is statistically significant if $t^{*}$ ( $t$-calculated) is greater than the critical t- value of \pm 1.96 under $95 \%$ (or $5 \%$ ) confidence levels and it is statistically insignificant if the $t^{*}$ is less than the tabulated value of \pm 1.96 under $95 \%$ ( or $5 \%$ ) confidence levels.

\subsection{Hypothesis one (H01): There is no significant relationship between Transactional leadership and} SMEs business expansion

Table 5: Transactional leadership and SMEs business expansion Stepwise Regression Results

\begin{tabular}{|l|c|l|l|l|}
\hline \multicolumn{5}{|c|}{\begin{tabular}{c} 
Dependent Variable: SMEsbusiness expansion \\
$\mathbf{R}^{2}=\mathbf{0} .5245$ \\
\hline \multicolumn{5}{|c|}{ = 12.09; Sig = 0.0012 }
\end{tabular}} \\
\hline $\begin{array}{l}\text { Independent } \\
\text { Variable }\end{array}$ & Beta & t-value & Pearson Correlation(r) & Probability value \\
\hline $\begin{array}{l}\text { Transactional } \\
\text { leadership }\end{array}$ & 14.9 & 2.67 & 0.7721. & 0.0001 \\
\hline
\end{tabular}

From table 5, the calculated t-value for TRSL is 2.67 and the critical value is given as 1.96 , under $95 \%$ confidence levels. Since the calculated t-value is greater than the critical value $(2.67>1.96)$, we therefore, reject the first null hypothesis (H01).We conclude that there is a significant relationship between Transactional leadership and business expansion

Also, by examining the overall fit and significance of the Business expansion model, it can be observed that the model have a good fit, as indicated by the relatively high value of the $F$-statistic, 12.09 and it is significant at the 5.0 per cent level. That is, the F-statistic value of 0.0012 is less than 0.05 probability levels.

More so, the $R^{2}$ (R-square) value of 0.5245 shows that the model does have a good fit too. It indicates that about 52.45 percent of the variation BE is explained by TRSL, while the remaining 47.55 percent is captured by the error term.

4.2 Hypothesis two (H02): $\mathrm{H}_{02}$ : Laissez-faire Leadership has not significantly influenced the employee job satisfaction

Table 6: Laissez-faire Leadership and employee job satisfaction Stepwise Regression results

\begin{tabular}{|c|c|c|c|c|}
\hline \multicolumn{5}{|c|}{$\begin{array}{r}\text { Stepwise Regression Analyses of Laissez-faire Leadershipon Outcome Variables } \\
\text { Dependent Variable: Employee job satisfaction(ES) } \\
\mathbf{R}^{2}=\mathbf{0 ~ . 8 7 2 9} ; \mathbf{F}=\mathbf{1 1 . 3 3} \text { Sig }=\mathbf{0 . 0 0 4 1}\end{array}$} \\
\hline $\begin{array}{l}\text { Independent } \\
\text { Variable } \\
\end{array}$ & Beta & t-value & Pearson Correlation $(\mathrm{r})$ & Probability value \\
\hline $\begin{array}{l}\text { Laissez-faire } \\
\text { Leadership }\end{array}$ & 1.14 & 2.29 & 0.7892 & 0.0132 \\
\hline
\end{tabular}

The calculated t-value for Laissez-faire Leadership (LFL) as found in table 4 was found to be 2.29 and also by rule of thumb, the critical value is 1.96 under $95 \%$ confidence interval levels. The calculated value of LFL is found to be greater than the tabulated value (that is; $2.29>1.96$ ), we thus, reject the second null hypotheses (H02). In conclusion, it was observed that Laissez-faire Leadership has significantly influenced the employee job satisfaction 
More so, by examining the overall fit and significance of the Employee satisfaction model, it was found to have a good fit, as indicated by the high $F$-statistic value of 11.33 and it is significant at the 5.0 per cent level. That is, the F-statistic value of 0.0041 is less than 0.05 .

The $R^{2}$ (R-square) value of 0.8729 shows that the model has a very good impact and fit also. It shows that about 87.29 percent of the variation inemployee satisfaction is explained by Laissez-faire Leadership, while the remaining 12.71 percentage unaccounted variation is captured by the error term.

\subsection{Hypothesis three (H03): Transformational leadership has no significant impact on Innovation} Table 7: Transformational leadership and Innovation Stepwise Regression Results

\begin{tabular}{|l|c|l|c|l|}
\hline \multicolumn{5}{|c|}{$\begin{array}{c}\text { Dependent Variable: Innovation(INV) } \\
\mathbf{R}^{2}=\mathbf{0 . 7 9 3 6} ; \mathbf{F}=\mathbf{1 6 . 8 6} \text {; Sig = 0.0032 }\end{array}$} \\
\hline Stepwise Regression Analyses of Transformational leadership(TRFL) on Outcome Variables \\
\hline $\begin{array}{l}\text { Independent Variable } \\
\text { leansformational }\end{array}$ & Beta & t-value & Pearson Correlation(r) & Probability value \\
\hline
\end{tabular}

Finally, from the regression result in table 7 the calculated t-value for TRFL is 4.14 and the tabulated value is 1.96. Since the $\mathrm{t}$-calculated is greater than the critical $\mathrm{t}$-value (that is, $4.14>1.96$ ) it also falls in the rejection region and hence, we may reject the third null hypothesis $\left(\mathbf{H O}_{\mathbf{3}}\right)$. The conclusion here is that Transformational leadership has a significant impact on Innovation.

The F-statistics equally showed that the overall result is significant, as indicated by the value of the $F$ statistic, 16.86 and it is significant at the 5.0 per cent level. That is, the F-statistic value of 0.0032 is less than 0.05 . Furthermore, the coefficient of determination (R-square), used to measure the goodness of fit of the estimated model, indicates that the model is also reasonably fit in prediction. The $R^{2}$ (R-square) value of 0.7936 shows that the Transformational leadership (TRFL) has a very good impact on Innovation (INV). It indicates that about 79.36 per cent of the variation in Innovation (INV) is explained by effective leadership through Transformational leadership (TRFL), while the remaining unaccounted variation of 20.64 percent is captured by the white noise error term.

\subsection{Discussion of Findings}

Findings from the study revealed that effective leadership through Transactional leadership has positive and significant relationship with business expansion. Transactional leaders' behaviours are influential in motivating the employees towards business expansion, to make them more aware of the task outcomes; they stimulate their other needs and develop their self - interest for the organization's performance. This is in-line with Rowe (2013) who carried out a survey of selected small scale enterprises in Nigeria as regard the effects of leadership styles on organizational performance and found out that transactional leadership style had a significant positive effect on performance. More so, Akpala (2014) also noted that leadership style and motivation exert strong effect on organizational development in Nigeria.

The study further showed that Laissez-faire Leadership has significantly influenced the employee job satisfaction. The employees are very much satisfied when manager delegates almost all authority and control to subordinates. The finding is in agreement with McGrath and MacMillan (2014) whose study showed that there is a significant relationship between Laissez-faire Leadershipadopted by managers and performance of the organizations.Effective Laissez-faire leadership style is seen as a potent source of management development and sustained competitive advantage, leadership style helps organization to achieve their current objectives more efficiently by linking job performance to valued rewards and by ensuring that employees have the resources needed to get the job done. Sun (2014) compared leadership style with the leadership performance in schools and enterprises, and found thatLaissez-faire leadership style had a significantly positive correlation with the organizational performance in both schools and enterprises.Fu-Jin (2012) opined that when executives use their leadership style to demonstrate concern, care and respect for employees, it would increase interest of employees in their work and enable them to put up better performance, thereby affecting their job satisfaction positively.

Lastly, it was found that Transformational leadership has significant impact on Innovation (and market share as well as branding). It showed that Understanding the effects of Transformationalleadership on organization development is also important because leadership is viewed by some researchers as one of the key driving forces for improving a firm's performance. Avolio(2014) found out from his analysis that effective Transformational leadership is seen as a potent source of management development and sustained competitive advantage for organizational performance improvement.Moore (2012) in his research within the United Way of America organization found out that there is a significant positive relationship between female transformational leaders and the revenue element of organizational effectiveness. 


\section{V.Conclusion And Recommendation}

It's important to note that the good leadership styles and right adoptions are necessary for provision of teamwork and ensuring everyone understands their roles within the SMEs. It means therefore that staffers who are properly motivate and guided by the management to work to achieve the desired results leads to increased efficiency, reduction of costs and improved performance.

Based on the findings above, the following are the recommendations that can be made for managerial policy and managerial practice:

i. SMEs Managers should consider formulating and implementing effective reward \& recognition systems. Managerial policies formulated should call for greater involvement in guiding subordinates to achieve organizational goals.

ii. Effective Leadership behaviors that have a strong positive relationship with organizational performance should be put into practice. It is therefore recommended that managers should: help others develop themselves; Guide to be rewarded for their work; be satisfied when others meet agreed-upon standards; provide recognition or rewards; tell others the standards they have to know to carry out their work and ask no more of others than what is absolutely essential.

iii. Transformational, Laissez-faire leadership and Transactional leadership styles are the best for the management of small busniness to be adopted in order for them to wax stronger in a global financial competitive environment.

\section{References}

[1]. Abdul Razak MN (2010) Keynote address by the Honorary Prime Minister at Invest Malaysia2010, Kuala Lumpur.

[2]. Adebayo, J. Y. (2003). Manufacturing Enterprises in Nigeria, Is Finance a constraint toPerformance? Journal of Economic Reform, $1(3)$.

[3]. Akpala .A. (2014). Igbo Cultural Factors that May Bear Management and Organization Performance in Nigeria .Business Management Topics, Vol. 1. Edited by EULImaga\&UJFEwurum.Enuguoktek publishers.

[4]. Alasan, S. L., \& Yakubu, A. L. (2011). An Empirical Study of Small Scale Financing in Nigeria.Journal of Unilorin Business School, 1(1), 87-96.

[5]. Amanda H. and Hodgkinson M.(2006), Re-thinking Leadership: a way forward for teaching leadership, Leadership \& Organization Development Journal Vol. 27(2)

[6]. Aremu, M. A. and Adeyemi, S. L. (2010). Small and Medium Scale Enterprises as A SurvivalStrategy for Employment Generation in Nigeria. Journal of Sustainable Development, $\quad$ 4(1): $200-206$.

[7]. Avolio, B. J. \& Bass, B. M. (2014). Multifactor Leadership Questionnaire: Manual and SamplerSet (3rd ed.). Redwood City, CA: Mind Garden

[8]. Ayyagari M, T. Beck and A. Demirguc-kunt (2003) Small and Medium Enterprises across theGlobe. A New database. World Bank, Development Research Group. Working paper 3127 Washington DC

[9]. Basil, A. N. O. (2005). Small and Medium Enterprises (SMES) in Nigeria: Problems and Prospects. Ph.D. Thesis, St. Clements University.

[10]. Bass, B. M. (1985). Leadership and Performance Beyond Expectation. New York: The Free Press.

[11]. Bass, B. M., \& Avolio, B. J. (1991). The implications of transactional and transformational leadership for individual, team, and organizational development. Research in Organizational Change and Development,4(1), 231.

[12]. Beaver G 2003, 'Small business: Success and failure', Strategic Change, Vol 12, No. 3, pp. 115

[13]. Central Bank Nigeria (2011). Statistical bulletin, Central Bank of Nigeria, 22(1)

[14]. Cole, N. D. (2004). Gender differences in perceived disciplinary fairness. Gender, Work \& Organization,11(3),254-277. http://dx.doi.org/10.1111/j.1468-0432.2004.00231.x

[15]. Cosson, M. (2003). The Entrepreneur: An Economic Theory (2nd ed.). Edward Elgar Publishers.

[16]. Davies J, Hides M and Powell J 2002, Defining the development needs of entrepreneurs inSMEs, Education + Training, Vol. 44, No. 8/9, pp. 406-412.

[17]. Denhardt, R. B., \& Denhardt, J. V. (2003). The New Public Service: an approach to reform. International Review of Public Administration, 8(1), 3-10.

[18]. Ekpeyoung, D.B.E. and M.O. Nyoung (1992). "small and medium scale EnterprisesDevelopment in Nigeria"; Seminar Paper on Economic Policy Research for Policy Design and Management in Nigeria, NCEMA/AEPC; Nigeria, April.

[19]. Essien, P., \& Udofia, A. (2006). Evolving a National Framework for the Emergence of a Strongand Virile Small and Medium Scale Industry Sub-Sector in Nigeria. A Seminar Paper Presented at MAN House.

[20]. Fatai, A.(2012). Small and Medium Scale Enterprises In Nigeria: The Problems And Prospects.Journal of political studies, Department of Political Science, Faculty of Social Sciences Lagos State University. 3(2)

[21]. Fry, L. W. (2003). Toward a theory of spiritual leadership. The leadership quarterly, 14(6), $693 \quad 727$. http://dx.doi.org/10.1016/j.leaqua.2003.09.001

[22]. Fu-Jin, M.K (2012) Financial Performance of Leasing Sector. The Case of China. Interdisciplinary Journal of Contemporary Research in Business, 2 (12), 339-345.

[23]. Gold, S. K. (2005). Entrepreneur's Notebook. Learning Ventures Press.

[24]. Goleman D. (2000), Leadership that Get Results, Harvard Business Review.

[25]. Hamidifar, F. (2009). A study of the relationship between leadership styles and employee jobsatisfaction at Islamic Azad University branches in Tehran. Iran: Islamic Azad University Branches.

[26]. Ihua, UB 2009, SMEs key failure-factors: 'A comparison between the United Kingdom and Nigeria', Journal of Social Science, Vol. 18, No. 3, pp. 199-207.

[27]. Ireghan, C. (2009). Small Scale Business Development in Nigeria. In Ireghan, C. (Ed.), The Place of Small and Medium Scale Business in the development of a nation State. Nigeria: Lagos, Kaycee Publishers

[28]. Kozak, R (2007) Small and Medium Forest Enterprises: Instrument of change in the developingWorld. Vancouver, British Colombia, University of British Columbia 
[29]. Lall, S. (1992). "Structural Problems of African Industry" In F.Steward, S.Lall and S.Wnagive(eds): Alternative Development Strategies in Sub-sahara Africa:Macmillian,London

[30]. Likert, R. (1961). New patterns of management. Retrieved fromhttp://www.jstor.org/stable239090

[31]. Luthar, H. K. (1996). Gender differences in evaluation of performance and leadership ability.Autocratic vs. democratic managers. Sex Roles, 35(5-6), 337-361.http://dx.doi.org/10.1007/BF01664773

[32]. McGrath and MacMillan, M.E (2014)Organization Behavior. New York. Wiley and sons inc.McGregor, D. (1960). The human side of enterprise. New York.

[33]. Meindl, J. R. (1990). Leadership-An Alternative to The Conventional Wisdom. Research inorganizational behavior, 12, 159-203.

[34]. Mogano, M. (2001). How to Start and run your own business. Graham and Trotman.

[35]. Moore, E. M. (2012). The impact of leadership style on organizational effectiveness:Leadership in action within United Way of America. Doctoral Dissertation,Capella University. NJ: Transaction.

[36]. Mullins, L. J. (1999). Management and Organizational Behaviour. London: Financial Times.

[37]. NCI. (2001). The thirteenth meeting of the national council on industry. Nigeria: The Role of Finance. Kuwait Chapter of Arabian Journal of Business and Management Review, 1(9): $\quad 79-93$.

[38]. Northouse, P. G. (2004). Leadership Theory and Practice. Pastoral Psychology, 56(4), 403-411.

[39]. Obadan, M.I (2003).”Poverty Reduction in Nigeria: The way forward" CBN Economic And Financial review Vol, 39: No 4

[40]. Ogechukwu, A (2006). The Role of Small Scale Industry in National Development in Nigeria. Texas Corpus Christi, Texas, United State. November 1-3 2006

[41]. Osoba, A. M. (2003). Towards the Development of Small Scale Industries in Nigeria. Nigerian Institute of Social and Economic Research

[42]. Rossouw D. and Vuuren L., (2013), Business Ethics, Oxford University Press.

[43]. Rowe, W. G. (2013). Creating Wealth in Organizations: The Role of Strategic Leadership. Academy of ManagementExecutive, 15: 81-94.

[44]. Sanders, J. O., \& Sanders, J. O. (2007). Spiritual leadership. A commitment to excellence for every believe. Sun, M. N (2014) . Leadership Development: Learning from Best Practices. Leadership andOrganization Development Journal, Volume 28, No. 5.

[45]. Tannenbaum, R., \& Schmidt, W. H. (1958). How to choose a leadership pattern (pp. 3-12). Institute of industrial relations.

[46]. Valdiserri GA and Wilson JL 2010, 'The study of leadership in small business organizations:Impact on profitability and organizational success', The Entrepreneurial Executive, Vol. 15, pp. 47-71.

[47]. Waldman, D. A., Bass, B. M., \& Yammarino, F. (1990). Adding to contingent-reward behaviorthe augmenting effect of charismatic leadership. Group \& Organization Management, $\quad 15(4), 381-394$. http://dx.doi.org/10.1177/105960119001500404

[48]. World Bank (1996). "Nigeria's Poverty in the Midst of Plenty: The challenge of GrowthWithinclusion" World bank Papers Washington D.C

[49]. Yukl, G. A. (1994). Leadership in Organization. Englewood Cliffs, New Jerseys: Prentice-Hall. 